\title{
Effect of Aluminum Nano-Particles on Microrelief and Dielectric Properties of PE+TIInSe 2 Composite Materials
}

\author{
E. M. Gojayev*, Kh. R. Ahmadova, S. I. Safarova, G. S. Djafarova, Sh. M. Mextiyeva \\ Azerbaijan Technical University, Baku, Azerbaijan \\ Email: "geldar-04@mail.ru
}

Received 21 October 2014; revised 20 November 2014; accepted 19 December 2014

Copyright (C) 2015 by authors and Scientific Research Publishing Inc.

This work is licensed under the Creative Commons Attribution International License (CC BY). http://creativecommons.org/licenses/by/4.0/

c) (7) Open Access

\begin{abstract}
The paper presents the results of studies surface microrelief, frequency-temperature characteristics of the imaginary part of the dielectric permittivity and dielectric loss of PE+TIInSe $\mathrm{e}_{2}$ composite materials in $25^{\circ} \mathrm{C}-150^{\circ} \mathrm{C}$ temperature and $25 \mathrm{~Hz}-1 \mathrm{MHz}$ frequency range before and after application of the aluminum nano-particles with a size of $50 \mathrm{~nm}$. The change in the amount of semiconductor filler TIInSe2 and aluminum nano-particles changes the state of the surface and the frequency-temperature characteristics of composite materials $\mathrm{PE}+\mathrm{xvol} . \% \mathrm{TlInSe} \mathrm{C}_{2}<\mathrm{Al}>$, which allows to obtain composites with the desired dielectric permittivity and dielectric loss.
\end{abstract}

\section{Keywords}

Surface Microrelief, Aluminum Nano-Particles, Dielectric Permeability, Tangent of the Angle Dielectric Loss

\section{Introduction}

Study of the dielectric properties of polymers over a wide temperature and frequency ranges is one of the most effective ways to establish the characteristics of their structure. However, the "response" of the polymer system to the action of the electric field of a certain frequency is not equivalent to the "mechanical response". Therefore, the method of dielectric loss can be used to identify softening of polymers. The maximum of dielectric loss may differ quite significantly from the temperature of the structural vitrification, as well as the frequency (at a given temperature corresponding to the maximum) may be different from the frequency of the mechanical vitrification. That mismatch of relaxation transitions corresponding to electrical or mechanical effects on the temperature or

*Corresponding author.

How to cite this paper: Gojayev, E.M., Ahmadova, Kh.R., Safarova, S.I., Djafarova, G.S. and Mextiyeva, Sh.M. (2015) Effect of Aluminum Nano-Particles on Microrelief and Dielectric Properties of PE+TIInSe ${ }_{2}$ Composite Materials. Open Journal of Inorganic Non-Metallic Materials, 5, 11-19. http://dx.doi.org/10.4236/ojinm.2015.51002 
frequency scale provides additional information about the levels of structural organization of the polymers.

Taking the above mentioned into consideration, this article studied the surface microrelief using atomic force microscope and the temperature and frequency dependences of PE+TIInSe $e_{2}$ and $\mathrm{PE}+\mathrm{TIInSe}_{2}$ compositions with aluminum nano-particles.

\section{Techniques of Experiment}

In scanning, the probe microscope study of surface microrelief and its local properties is carried out with the help of specially prepared probes in the form of needles. The dimension of the working part of such probes is about $10 \mathrm{~nm}$. The typical distance between the probe and the sample surface in probe microscopes is equal 0.1 $10 \mathrm{~nm}$. Operation of the probe microscopes based on different types of interaction of the probe with the surface [1]. The process of scanning of the surface in scanning probe microscope is similar to the motion of the electron beam across the screen in the TV cathode-ray tube. Probe moves along the line first in the forward direction and then in the opposite one, then moves to the next line. The movement of the probe is carried out using a scanner in small steps under the effect of saw-tooth voltage, generated by digital to analog converters. Registration of the information about surface is carried out, as a rule, on direct pass under two conditions: in the process of scanning probe must touch points on the surface and in each case only one of its points. And if the scanning probe cannot reach some areas of the surface (e.g., when the samples have the highest portions of the relief), the relief only partially is restored. And the greater the number of points touching the probe, the more reliable is possible to reconstruct the surface.

The test samples were prepared as follows: a polymer powder is mixed with a powder of a semiconductor material TIİnSe2 and aluminum nano-particles. After that, the mixture placed between aluminum foil sheets is compressed into $100-\mu \mathrm{m}$-thick films at the melting temperature of the polymer matrix and a press sure of 15 MPa. The prepared samples with the foil are quenched in water, and the foil is removed. The obtained samples are useful for studying the properties of electrets. Research conducted at the facility described in [2]. Composites with additives investigated $\mathrm{x}=0,1,3,5,7,10 \mathrm{wt} \%$ and $\mathrm{y}=3 ; 5 ; 7 ; 10 \mathrm{wt} \%$.

To calculate the dielectric permittivity of the sample thickness and diameter of the upper electrode (for determining an area) is measured automatically using calipers. For this purpose, the sample is placed between two flat electrodes of circular shape. Capacitance and dielectric loss tangent are measured at the same time [3].

The dielectric permittivity of the compositions is calculated from the measured capacitance values, the thickness of the sample and the area of the electrodes. The dielectric permittivity $\varepsilon$ is calculated according to the formula

$$
\varepsilon=\frac{C d}{\varepsilon_{0} S},
$$

where $C$-measured electrical capacitance of the sample, $F$; $\varepsilon_{0}=8.85 \times 10^{-12} \mathrm{~F} / \mathrm{m}$; $d$-diameter of the sample, $\mathrm{m}$; $\mathrm{S}$-area of the sample, $\mathrm{m}^{2}$.

Dielectric loss tangent $\operatorname{tg} \delta$ is measured directly. Thus, for each of the selected dielectrics must be measured capacitance and dielectric loss tangent corresponding to $1 \mathrm{~Hz}$ frequency.

The sample is mounted between two electrodes in the measuring cell. Then it is heated in a cell (the heater is mounted in the cover) with a constant rate of $2 \mathrm{~K} / \mathrm{min}$. The sample temperature is recorded using a thermocouple and the dielectric losses-with the help of the measuring bridge LCK E7-8 heating at a constant rate achieved by three-LAT-system.

\section{Results and Discussion}

As a result, we have obtained planar surface image for PE+xvol.\%TlInSe $e_{2}$ composites of size $16 \times 10^{3} \times 16 \times$ $10^{3} \mathrm{~nm}$ (Figure 1(a) and Figure 1(b)), respectively. From Figure 1(a), Figure 1(b), which shows 3D (threedimensional) images of the same sections it is seen that the surface relief (topography) of the compositions varies with the volume amount of the filling nano-particles [4]-[6].

Analysis of AFM images histograms (Figure 2(a) and Figure 2(b)) shows that the uniformity of the surface varies up to $25 \mathrm{~nm}$. It is seen that in the boundary layer of the compositions yet is observed some rough edges. Rather, they are connected with the fact that the destruction of the binding forces leaves on the surface not individual atoms but their groups-clusters. This is also evidenced from Fourier spectrum obtained by AFM method 


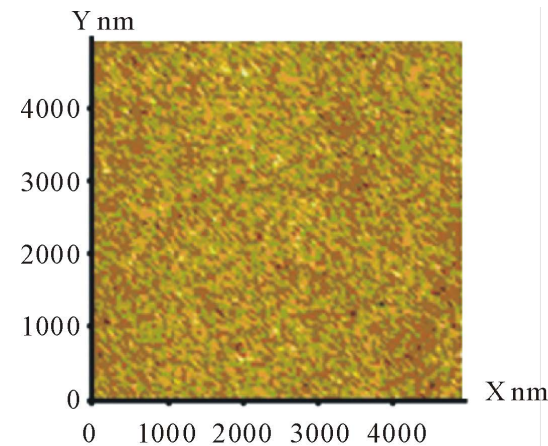

$\mathrm{PE}+3 \mathrm{vl} . \% \mathrm{TlInSe}_{2}$

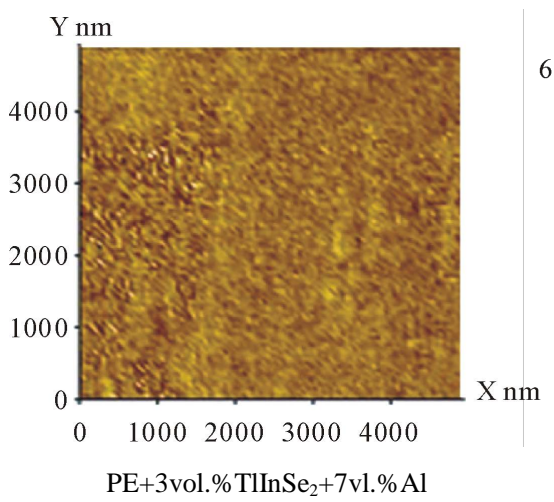

Phase a.u

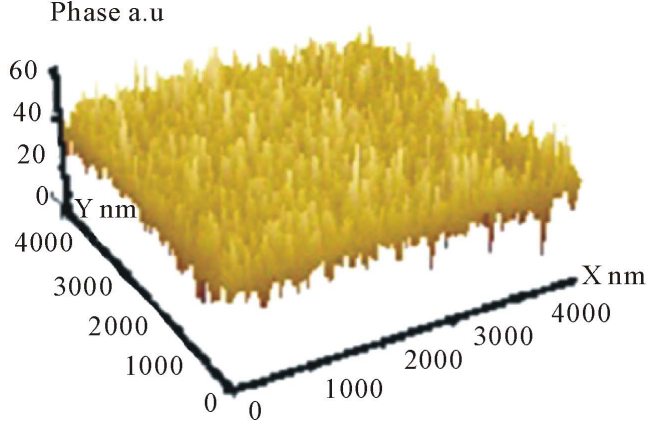

PE+3vl.\%TlInSe 2

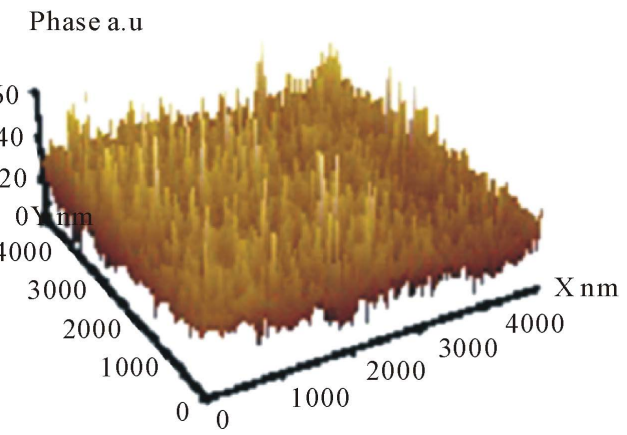

$\mathrm{PE}+3 \mathrm{vol} . \% \mathrm{TlInSe}_{2}+7 \mathrm{vl} . \% \mathrm{Al}$
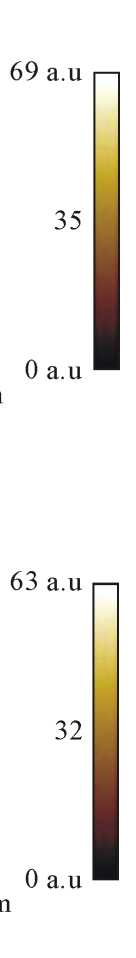

(a)

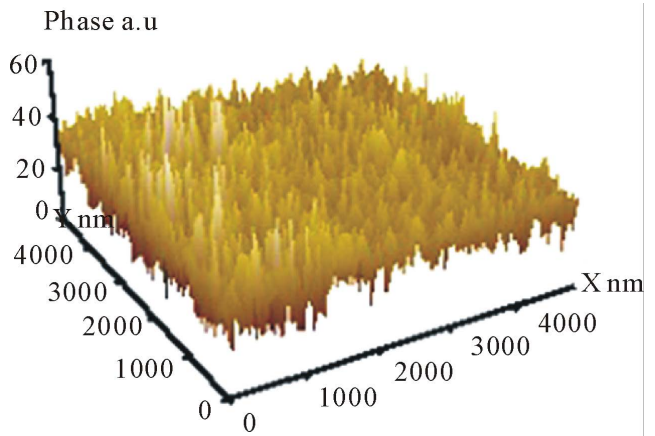

PE+5vol.\%TlInSe 2

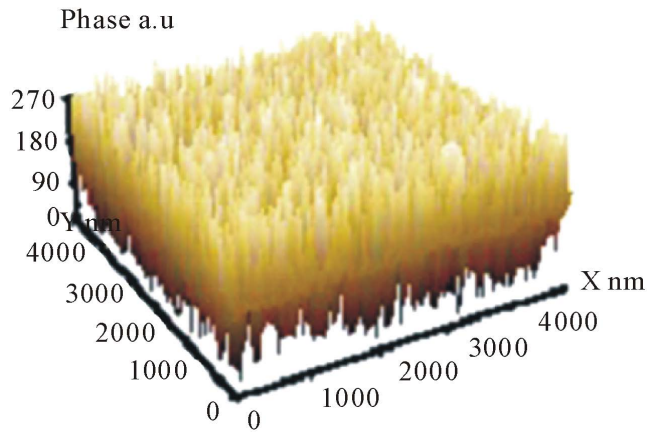

$\mathrm{PE}+5 \mathrm{vol} . \% \mathrm{TlInSe}_{2}+5 \mathrm{vl} . \% \mathrm{Al}$

(b)

Figure 1. Planar (a) and 3D (b) images of the surface of composites. 


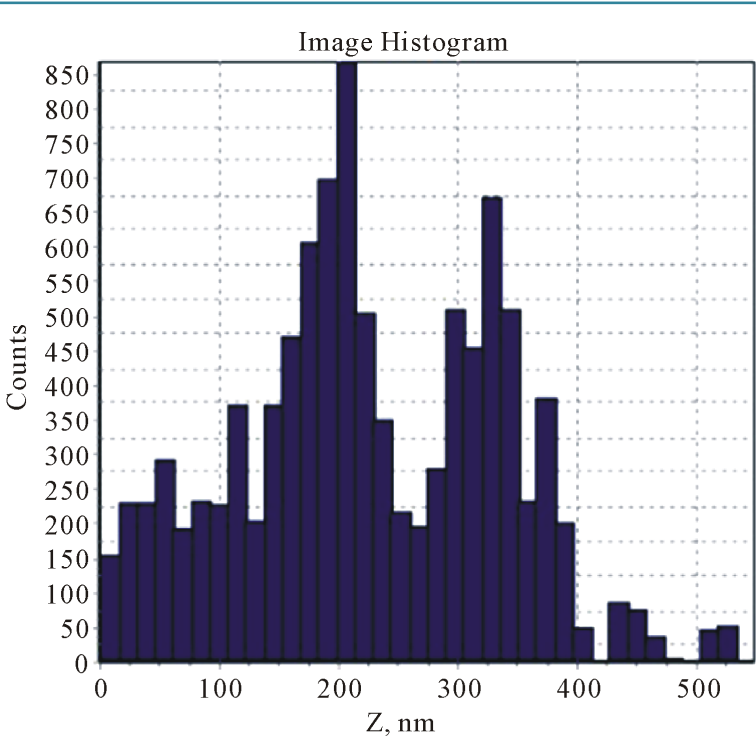

Roughness Average $89.75 \mathrm{~nm}$

Root Mean Square $\quad 109.25 \mathrm{~nm}$

$\mathrm{PE}+3 \mathrm{vl} . \% \mathrm{TlInSe}_{2}$

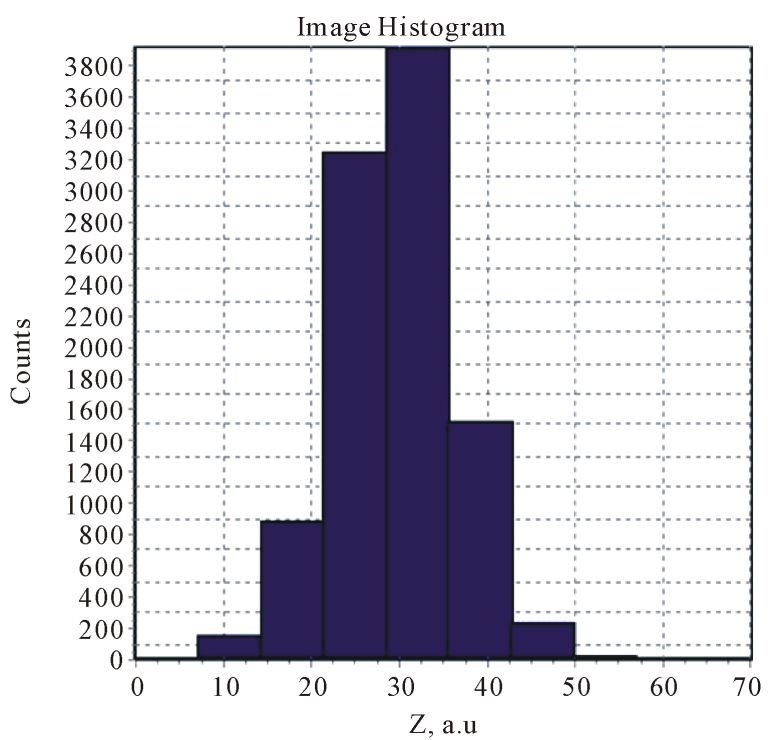

Roughness Average 5.18 a.u

Root Mean Square 6.64 a.u

$\mathrm{PE}+3 \mathrm{vol} . \% \mathrm{TlInSe} \mathrm{e}_{2}+7 \mathrm{vl} . \% \mathrm{Al}$

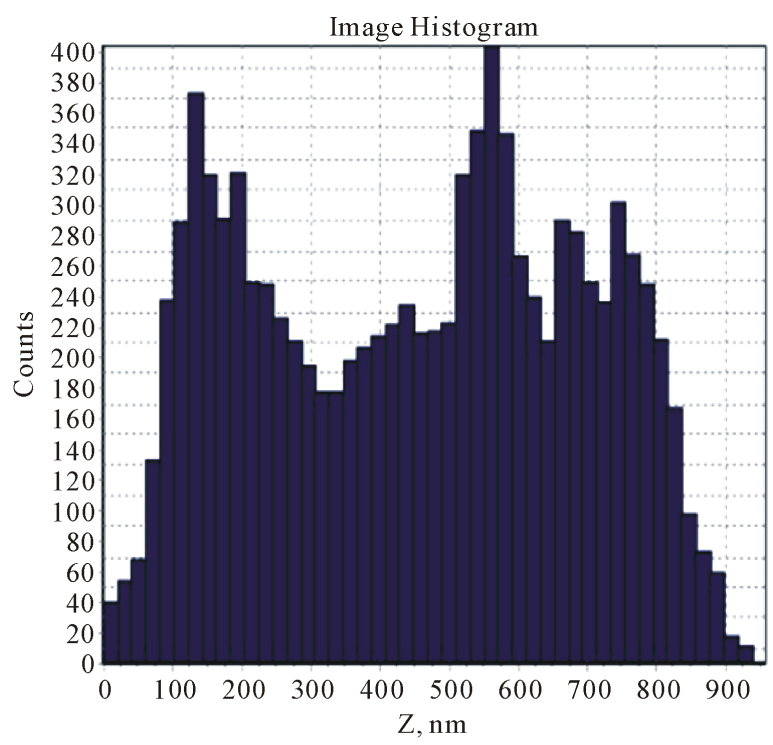

Roughness Average $204.17 \mathrm{~nm}$

Root Mean Square $234.60 \mathrm{~nm}$

PE+5vol.\%TlInSe

(a)

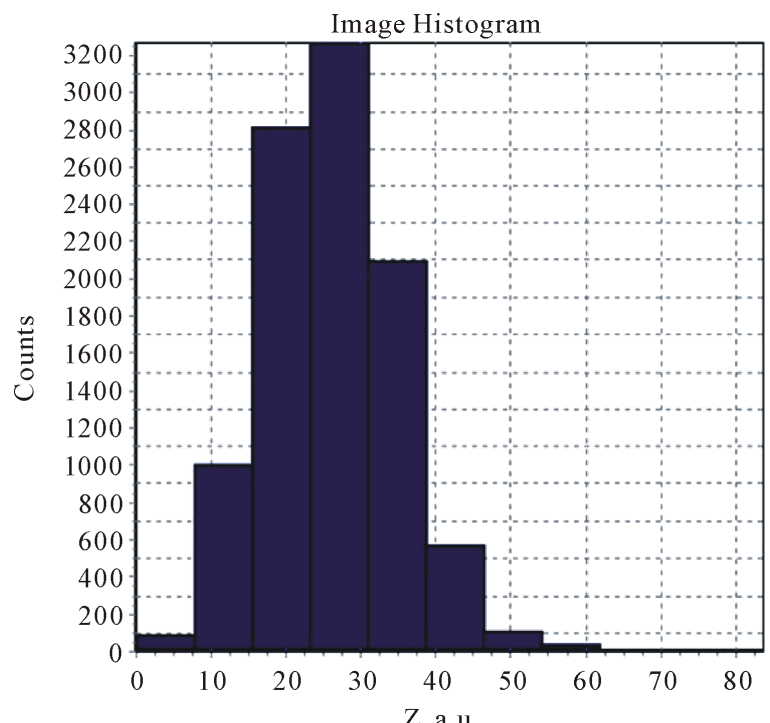

Roughness Average 6.81 a.u

Root Mean Square 8.77 a.u

PE+5vol.\%TlInSe $e_{2}+5 \mathrm{vl} . \% \mathrm{Al}$

(b)

Figure 2. Surface histogram composites.

(Figure 3(a) and Figure 3(b)). The concentration of the spectrum in the center of the image shows that the surface particles have approximately the same dimensions, i.e. are commensurable.

Results of the study of frequency-temperature dependences of the imaginary part of the dielectric permittivity and dielectric loss tangent of the compositions PE+xvol.\%TlInSe $2(1 \leq \mathrm{x} \leq 10)$ are shown in Figures 4-7.

Figure 4 shows the dependence of the imaginary part of the dielectric permittivity with temperature in the range of $20^{\circ} \mathrm{C}-150^{\circ} \mathrm{C}$ for composites $\mathrm{PE}+\mathrm{xvol}$.\%TlInSe $2(1 \leq \mathrm{x} \leq 10)$.

As follows from Figure 4, the imaginary part of the dielectric permittivity increases with temperature in 

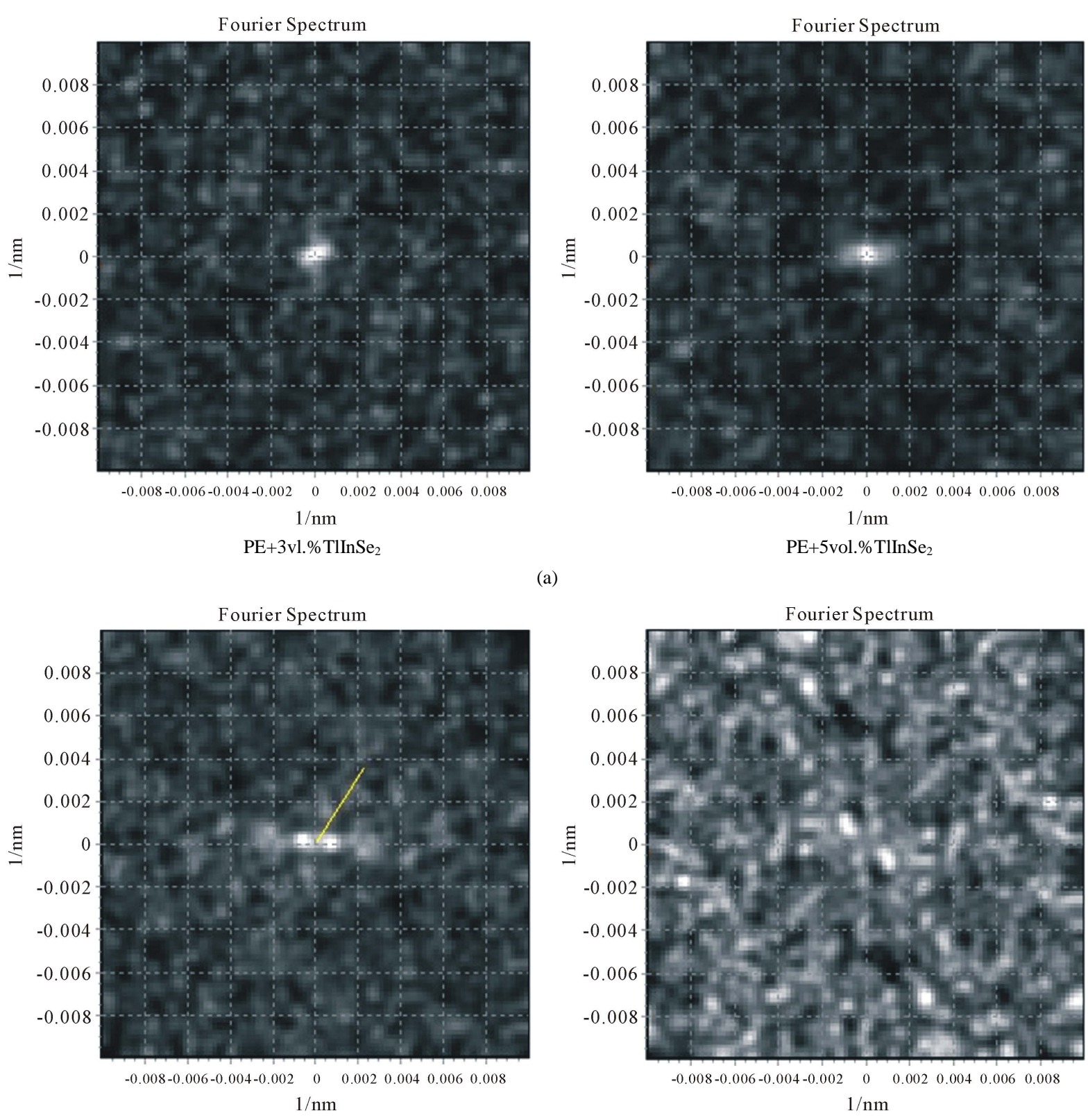

a)

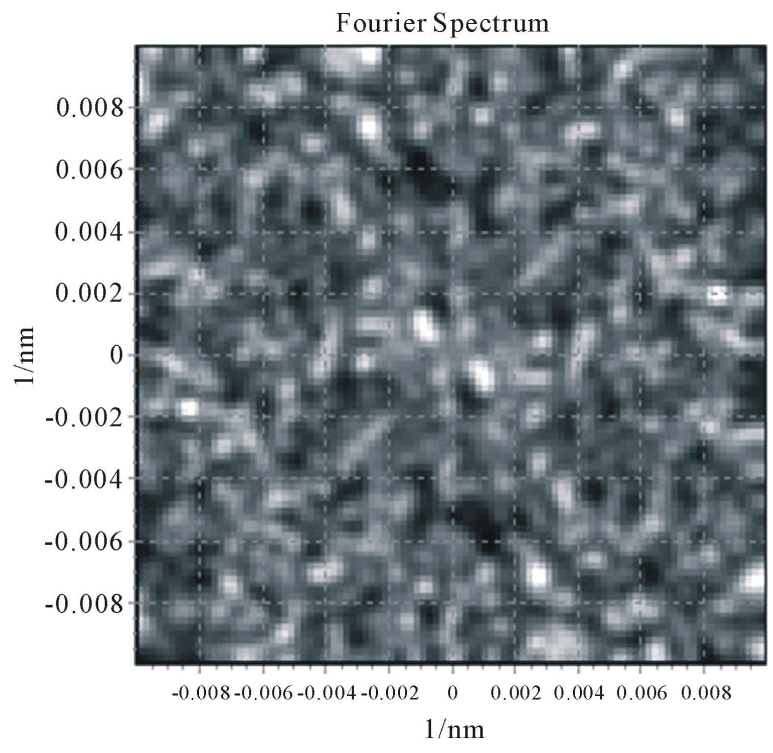

(b)

$\mathrm{PE}+5 \mathrm{vol} . \% \mathrm{TlInSe} \mathrm{e}_{2}+5 \mathrm{vl} . \% \mathrm{Al}$

Figure 3. Fourier spectrum of the surface of the composites.

$\mathrm{PE}+\mathrm{xvol. \% TlInSe} \mathrm{e}_{2}$ composite materials with an increase in the additive from 1 to 5 vol.\%. In general, for investigated composites the variation $\varepsilon^{\prime \prime}(\mathrm{T})$ is not significantly different. However, for the composite PE $+5 \mathrm{vol} . \%$ $\mathrm{TlInSe}_{2}$ at a temperature $600^{\circ} \mathrm{C}$ a mild maximum is revealed. Dependence $\varepsilon "(\mathrm{~T})$ shows that at low additive content imaginary part of the dielectric permittivity remains substantially constant. And when the amount of additives in TlInSe $e_{2}$ increases up to 5 vol.\%, increase in $\varepsilon^{\prime \prime}(\mathrm{T})$ and the further reduction with increasing of the temperature occurs. Changes in the imaginary part of the dielectric permittivity with temperature for this composite are substantially different. Firstly, at $25^{\circ} \mathrm{C}$, imaginary part of the dielectric permittivity increases by three times. In $60^{\circ} \mathrm{C}-100^{\circ} \mathrm{C}$ temperature range, relatively moderate reduction occurs. Further, from $100^{\circ} \mathrm{C}$ to $125^{\circ} \mathrm{C}$ sharp decrease in the imaginary part of the dielectric constant takes place. In this temperature range, the imaginary part of the dielectric permittivity reduces by 3.5 times. Subsequently up to $150^{\circ} \mathrm{C}$ moderate decrease of $\varepsilon$ " occurs. 
Results of the study of the temperature dependence of the dielectric loss tangent of composite materials $\mathrm{PE}+\mathrm{xvol} \% \mathrm{TlInSe}_{2}(1 \leq \mathrm{x} \leq 10)$ are shown in Figure 4(b). As can be seen from Figure 4(b), a change of tg $\delta$ with temperature for composites with $\mathrm{x}=1 ; 3$ in the temperature range investigated does not practically occur. For $\mathrm{PE}+5 \mathrm{vol} \% \mathrm{TlInSe} \mathrm{T}_{2}$ composite $\operatorname{tg} \delta$ at low temperatures is relatively high, but with increasing temperature decreases to a stable value (0.0076). For the composite with $\mathrm{x}=10$ in $250^{\circ} \mathrm{C}-100^{\circ} \mathrm{C}$ temperature range a slight increase in $\operatorname{tg} \delta$, in the range of $100^{\circ} \mathrm{C}-125^{\circ} \mathrm{C}$ sharp decrease from 0.0373 to 0.0096 , and further a slight decrease occurs.

We investigated the frequency and temperature dependence of composite materials $\mathrm{PE}+\mathrm{xvol} . \% \mathrm{TlInSe} \mathrm{e}_{2}<\mathrm{Al}>$ with aluminum nano-particles. The results are shown in Figure 5(a) and Figure 5(b).

As can be seen from Figure 5(a), in the investigated temperature range of $250^{\circ} \mathrm{C}-150^{\circ} \mathrm{C}$ the imaginary part

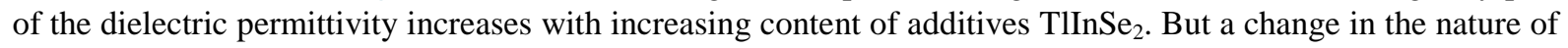
overall identical for the three composites, where $(x=3,5,7)$, respectively with the addition of the aluminum nano-particles in an amount of $y=7 ; 5 ; 3$.

Similarly occur changes of $\varepsilon^{\prime \prime}(\mathrm{T})$ for the composite PE+10vol.\%TlInSe $\mathrm{P}_{2}+10 \mathrm{vl}$ \% Al. However, note that in the entire temperature range $\varepsilon^{\prime \prime}(\mathrm{T})$ in magnitude greater than in other composites. In the temperature range of $850^{\circ} \mathrm{C}$ $100^{\circ} \mathrm{C}$ is observed a significant increase, and further moderate decrease in $\varepsilon^{\prime \prime}(\mathrm{T})$.

We investigated the frequency dependence of the imaginary part of the dielectric permittivity and dielectric loss tangent of composites in the frequency range $25 \mathrm{~Hz}-1 \mathrm{MHz}$. As can be seen from Figure 6(a), change of the imaginary part of the dielectric permittivity against the frequency for composites with $\mathrm{x}=3$; 5 ; 10 are of the same nature. Is typical of all three composites in the range of $100 \mathrm{kHz}-1 \mathrm{MHz}$ relatively high decrease, slow decrease up to $1 \mathrm{kHz}$, and then an inversion of the imaginary parts of the permittivity occurs. At $200 \mathrm{~Hz}$ a deep minimum is observed and further an increase of the imaginary part of the permittivity occurs. Nature of the change of the imaginary part of the dielectric permittivity of the composite with the addition of $\mathrm{x}=1 \mathrm{vol}$. $\%$ before detecting an inversion has identical character. However, at frequencies of $500 \mathrm{~Hz}, 100 \mathrm{~Hz}$ deep minima, and between them at $200 \mathrm{~Hz}$ pronounced peak is observed.

The dielectric loss tangent for the above mentioned composites with the addition of $\mathrm{TlInSe}_{2}$ have been investigated.

As can be seen from Figure 6(b), a plot $\operatorname{tg} \delta(v)$ is identical with the character of $\varepsilon^{\prime \prime}(v)$. For composites with $\mathrm{x}=$ 3; 5; 10 is revealed a single deep minimum at a frequency of $200 \mathrm{~Hz}$ and a sign inversion of $\operatorname{tg} \delta$ at the frequency of $1 \mathrm{kHz}$; for the composite with $\mathrm{x}=1$ also a sign inversion for $\operatorname{tg} \delta$ at the same frequency, deep minima at frequencies of 100 and $500 \mathrm{~Hz}$ and clear maximum at a frequency of $200 \mathrm{~Hz}$ is detected.

Results of the study of the imaginary part of the dielectric permittivity and dielectric loss of composites

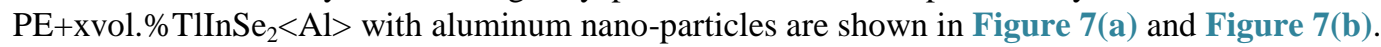

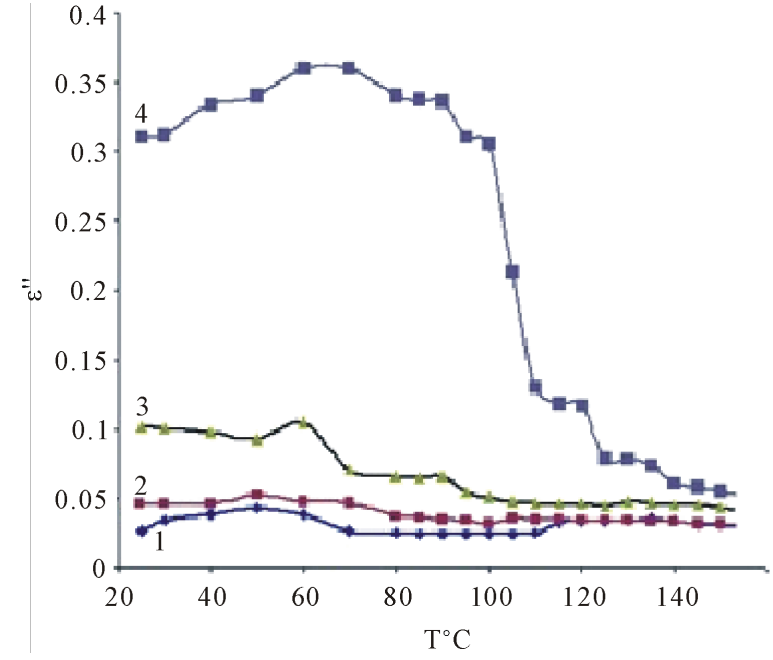

(a)

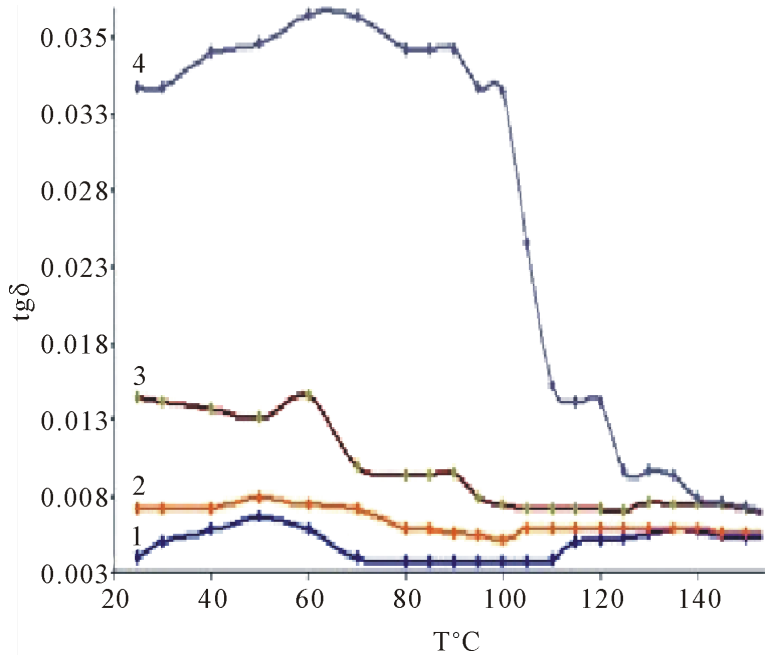

(b)

Figure 4. Temperature dependence of the imaginary part of dielectric permittivity (a) and $\operatorname{tg} \delta$ (b) composite materials

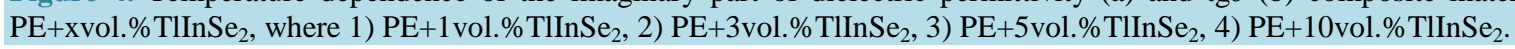




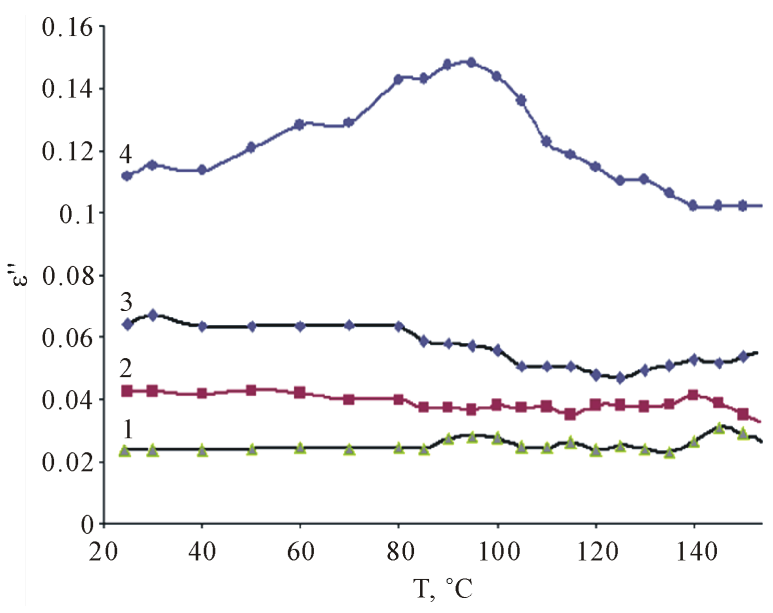

(a)

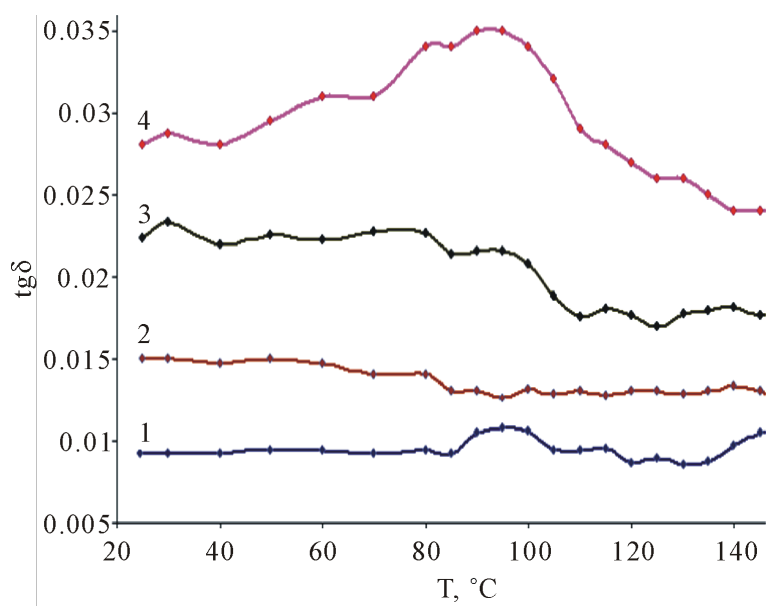

(b)

Figure 5. Temperature dependence of the imaginary part of dielectric permittivity (a) and $\operatorname{tg} \delta$ (b) composite materials $\mathrm{PE}+\mathrm{xvol} . \% \mathrm{TlInSe}_{2}<\mathrm{Al}>$, where 1) $\left.\left.\mathrm{PE}+3 \mathrm{vol} . \% \mathrm{TlInSe} \mathrm{e}_{2}+7 \mathrm{vl} . \% \mathrm{Al}, 2\right) \mathrm{PE}+5 \mathrm{vol} . \% \mathrm{TlInSe}_{2}+5 \mathrm{vl} . \% \mathrm{Al}, 3\right) \mathrm{PE}+7 \mathrm{vol}_{0} \% \mathrm{TlInSe}_{2}+$ 3vl.\%Al, 4) PE+10vol.\%TlInSe ${ }_{2}+10 \mathrm{vl} . \% A l$.

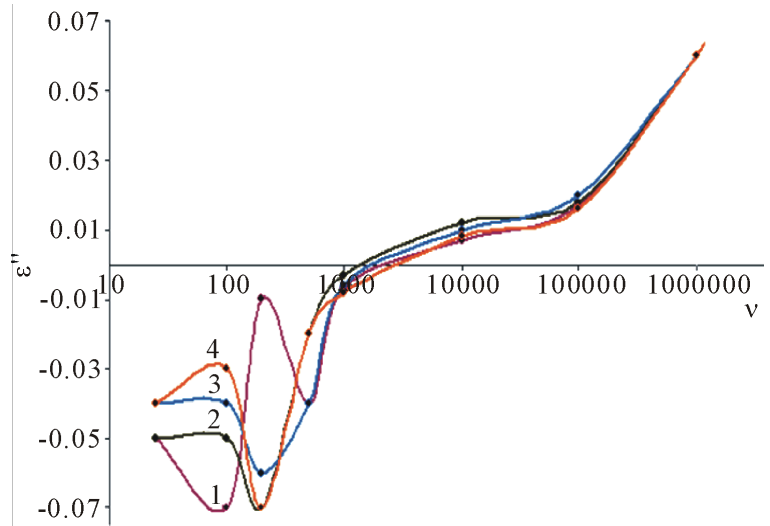

(a)

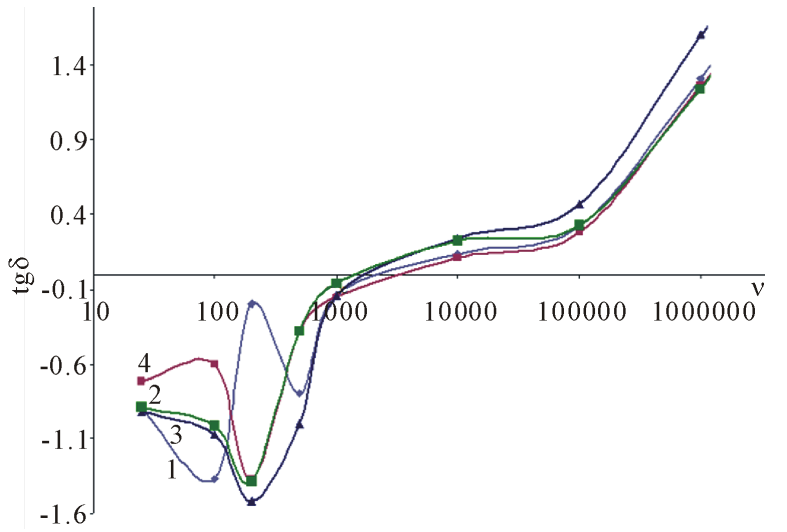

(b)

Figure 6. The frequency dependence of the imaginary part of dielectric permittivity (a) and $\operatorname{tg} \delta$ (b) for composite materials

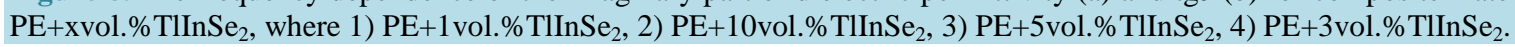

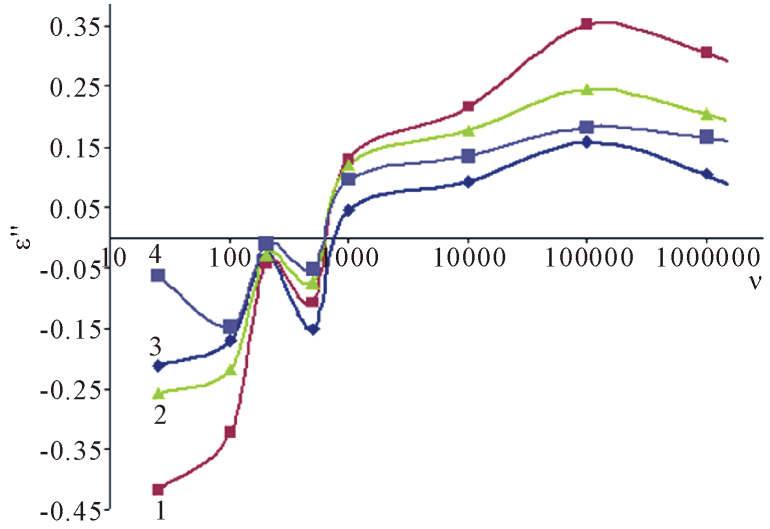

(a)

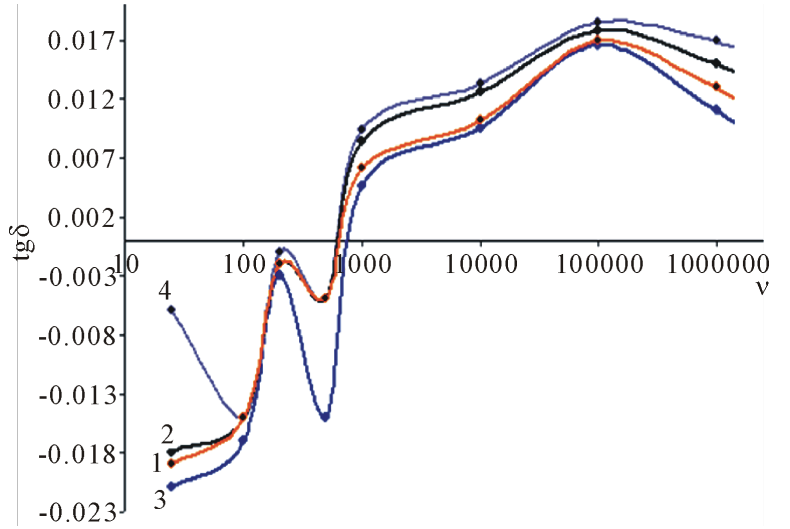

(b)

Figure 7. Frequency dependence of the imaginary part of dielectric permittivity (a) and tg $\delta$ (b) composite materials $\mathrm{PE}+\mathrm{xvol} . \% \mathrm{TIInSe} \mathrm{e}_{2}<\mathrm{Al}>$, where 1) $\mathrm{PE}+5$ vol.\%TlInSe ${ }_{2}+5 \% \mathrm{Al}$, 2) $\left.\mathrm{PE}+3 \mathrm{vol} . \% \mathrm{TlInSe}_{2}+7 \% \mathrm{Al}, 3\right) \mathrm{PE}+7 \mathrm{vol}_{0} \% \mathrm{TlInSe}_{2}+3 \% \mathrm{Al}$, 4) $\mathrm{PE}+10 \mathrm{vol} \% \mathrm{TlInSe} \mathrm{S}_{2} 10 \% \mathrm{Al}$. 
As can be seen from Figure 7(a), for these composite materials at high frequencies there is a slight change in $\varepsilon^{\prime \prime}$. Inversion of the sign occurs at a frequency of $1 \mathrm{kHz}$, a deep minimum at a frequency of $500 \mathrm{~Hz}$ and a pronounced maximum at a frequency of $200 \mathrm{~Hz}$.

Figure 7(b) shows the results of a study of dielectric loss of composites with aluminum nano-particles depending on the frequency. Studies were carried out in the same frequency range. The results shown in Figure 7(b) imply that at the frequency of $800 \mathrm{~Hz}$ inversion of $\operatorname{tg} \delta$ sign and at a frequency of $500 \mathrm{~Hz}$ deep minima, and at $200 \mathrm{~Hz}$ bright maximum is observed.

In general, the change in the imaginary part of the dielectric permittivity and dielectric loss frequency change occurs in a similar manner.

In a further increase in TlInSe $e_{2}$ filler content to 10 vol\% in the range $25^{\circ} \mathrm{C}-100^{\circ} \mathrm{C} \varepsilon$ " value increases for 6 times. In the range $100^{\circ} \mathrm{C}-125^{\circ} \mathrm{C} \varepsilon$ " decreases approximately four times and thereafter remains unchanged. For the investigated composites regular increase of $\varepsilon$ " with increasing filler content is observed.

Also the frequency dependence of $\varepsilon^{\prime \prime}$ has been investigated. The studies were conducted in the frequency range of $25 \mathrm{~Hz}-1 \mathrm{MHz}$. Results of the study are shown in Figure 4.

As follows from figure, character of changes for $\varepsilon$ " depending on the frequency is the same for compositions with $\mathrm{x}=3$; 5 and 10. With an increase in frequency from $25 \mathrm{~Hz}$ to $200 \mathrm{~Hz}$ is revealed the deep minima, in the range of $200 \mathrm{~Hz}-1 \mathrm{kHz}$ sharp increase $\varepsilon^{\prime \prime}$. Further increase in frequency up to $1 \mathrm{MHz}$ leads to increase in $\varepsilon^{\prime \prime}$. $\varepsilon^{\prime \prime}(v)$ for PE +1 vol.\% composite significantly different. At frequencies of $100 \mathrm{~Hz}$ and $500 \mathrm{~Hz}$ are observed deep minima, and between them at a frequency of $200 \mathrm{~Hz}$ bright maximum. In the frequency range of $500 \mathrm{~Hz}-1 \mathrm{MHz}$ character of change of $\varepsilon$ " is not different from other composites.

Analysis of the experimental results of the temperature dependence of dielectric permittivity of $\mathrm{PE}+\mathrm{xvol} . \%$ $\mathrm{TIInSe}_{2}$ and $\mathrm{PE}+\mathrm{xvol}$ \% $\% \mathrm{TIInS} \mathrm{e}_{2}<\mathrm{Al}>$ composites shows that in general, variation $\varepsilon^{\prime \prime}(\mathrm{t})$ in these materials are same. However, with increasing amounts of filler (Figure 4(a)) increasing $\varepsilon^{\prime \prime}$ values is observed. This behavior of the dielectric permittivity of the composite with semiconductor filler is largely determined by the MaxwellWagner polarization. The surface energy of the composite structure components becomes unstable and TlInSe ${ }_{2}$ particles form clusters, the surface of which is less than the sum of the surface of their constituent particles. Increasing the number of clusters with increasing bulk filler content is accompanied by decrease in the dielectric layer between the particles. It leads to increase in electric capacity and accordingly $\varepsilon "$. In the composites obtained with the addition of aluminum nano-particles with size of $50 \mathrm{~nm}$, the character of the dielectric permittivity variation does not change. However, with increasing of $\mathrm{Al}$ content in the composite the value of $\varepsilon$ " decreases throughout the temperature range studied. This is probably due to the fact that the aluminum nano-particles occupy vacancies-defects on the surface of the composites. This promotes the change in the electric resistance and the imaginary part of the dielectric permittivity. Using aluminum nano-particles allows obtaining composites having the desired dielectric permittivity and dielectric loss. Analysis of the frequency dependence of the dielectric permittivity and dielectric loss of $\mathrm{PE}+\mathrm{xvol} . \% \mathrm{TlInSe}_{2}$ composites and the same composite with aluminum nano-particles show that $\varepsilon^{\prime \prime}$ and $\operatorname{tg} \delta$ significantly reduced. At introduction in the composites aluminum nano-particles isolated clusters is formed alongside with the semiconductor particles. Aluminum nano-particlesconductive clusters randomly distributed in the PE matrix. Increasing $\mathrm{Al}$ content in the composite leads to an increase in the number of nano-particles per cross section of the composite, which is equivalent to the proportion of $\mathrm{Al}$ in the total thickness of the composite-sample. Closed each other through-thickness sample clusters can be considered as active resistance connected between the electrodes. Since they have high compared with PE+ xvol.\%TlInSe $e_{2}$ composites conductivity, it can be assumed that the resistance of the composite will be mainly determined by contacts between $\mathrm{Al}$ nano-particles. At the boundaries of clusters in the alternating electric field an accumulation and redistribution of free charges occurs, which changes the initial internal electric field. It is known that at low frequencies, internal electric fields are distributed accordingly conductivity and high frequencies-respectively the dielectric permittivity. Therefore, the decrease $\varepsilon$ " and $\operatorname{tg} \delta$ with increasing content of aluminum nano-particles can be explained by the appearance of a relatively strong internal field in semiconductors and nano-clusters.

\section{Conclusion}

In conclusion, we study the materials at high frequencies and reveal that, the imaginary part of the permittivity is negative. In these frequencies, electronic and ionic polarization is in the main role. These materials have found 
application in the creation of new electronic devices.

\section{References}

[1] Mironov, V. (2004) Fundamentals of the Scanning Probe Microscopy. Technosphere, Moscow, 197-201

[2] Gojaev, E.M., Maharramov, A.M., Zeynalov, S.H.A., Osmanova, S.S. and Allakhyarov, E.A. (2010) Crown Electrets Based on High Density Polyethylene Composites with Semiconductor Filler TlGaSe $\mathrm{T}_{2}$. Electronic Materials Processing, No. 6, 266.

[3] Zhigaeva, I.A. and Nikolaev, V.E. (2012) Study Based on Fluoropolymer Coronoelectrets-32L by Thermally Stimulated Relaxation of the Surface Potential. Education and Science Minister Modern Trends in Chemistry and Technology of Polymeric Materials. International Conference Abstracts St.-Petersburg, 38-39.

[4] Mamedov, G.A., Godzhaev, E.M. and Magerramov, A.M. (2011) Study of Surface Topography by Atomic Force and Dielectric Properties of Compositions of High-Density Polyethylene with an Additive TlGaSe ${ }_{2}$. Electronic Materials Processing, 47, 94-98.

[5] Gojayev, E.M., Safarova, S.S., Kafarova, D.M. Gulmammadov, K.D. and Ahmedova, J.R. (2013) Study of Surface Microrelief and Dielectric Properties of the Compositions of PP+TlIn $0,98 \mathrm{Ce}_{0}, 02 \mathrm{Se}_{2}$. Electronic Materials Processing, 49, 267-271.

[6] Godzhaev, E.M., Magerramov, A.M., Zeinalov, Sh.A., Osmanova, S.S. and Allakhyarov, E.A. (2011) Coronoelectrets Based on Composites of High Density Polyethylene with $\mathrm{T}_{1} \mathrm{GaSe}_{2}$ Semi-Conductor Filler. Surface Engineering and Applied Electrochemistry, 46, 615-619. http://dx.doi.org/10.3103/S106837551006013X 
Scientific Research Publishing (SCIRP) is one of the largest Open Access journal publishers. It is currently publishing more than 200 open access, online, peer-reviewed journals covering a wide range of academic disciplines. SCIRP serves the worldwide academic communities and contributes to the progress and application of science with its publication.

Other selected journals from SCIRP are listed as below. Submit your manuscript to us via either submit@scirp.org or Online Submission Portal.
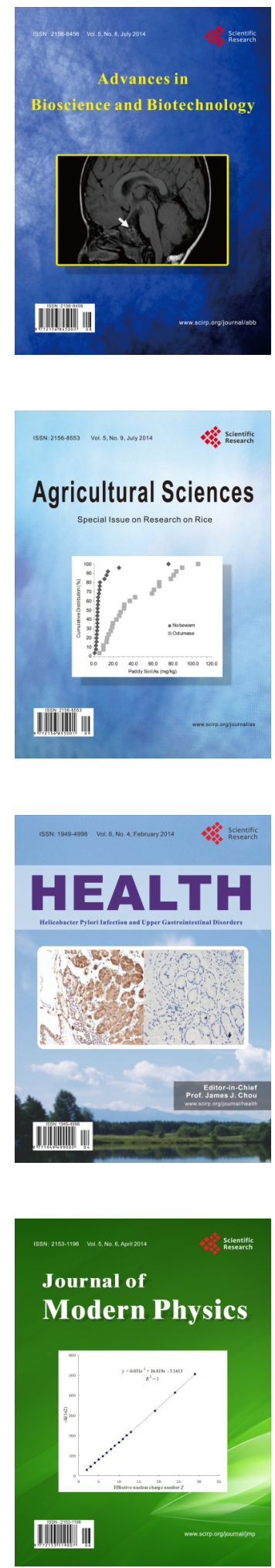
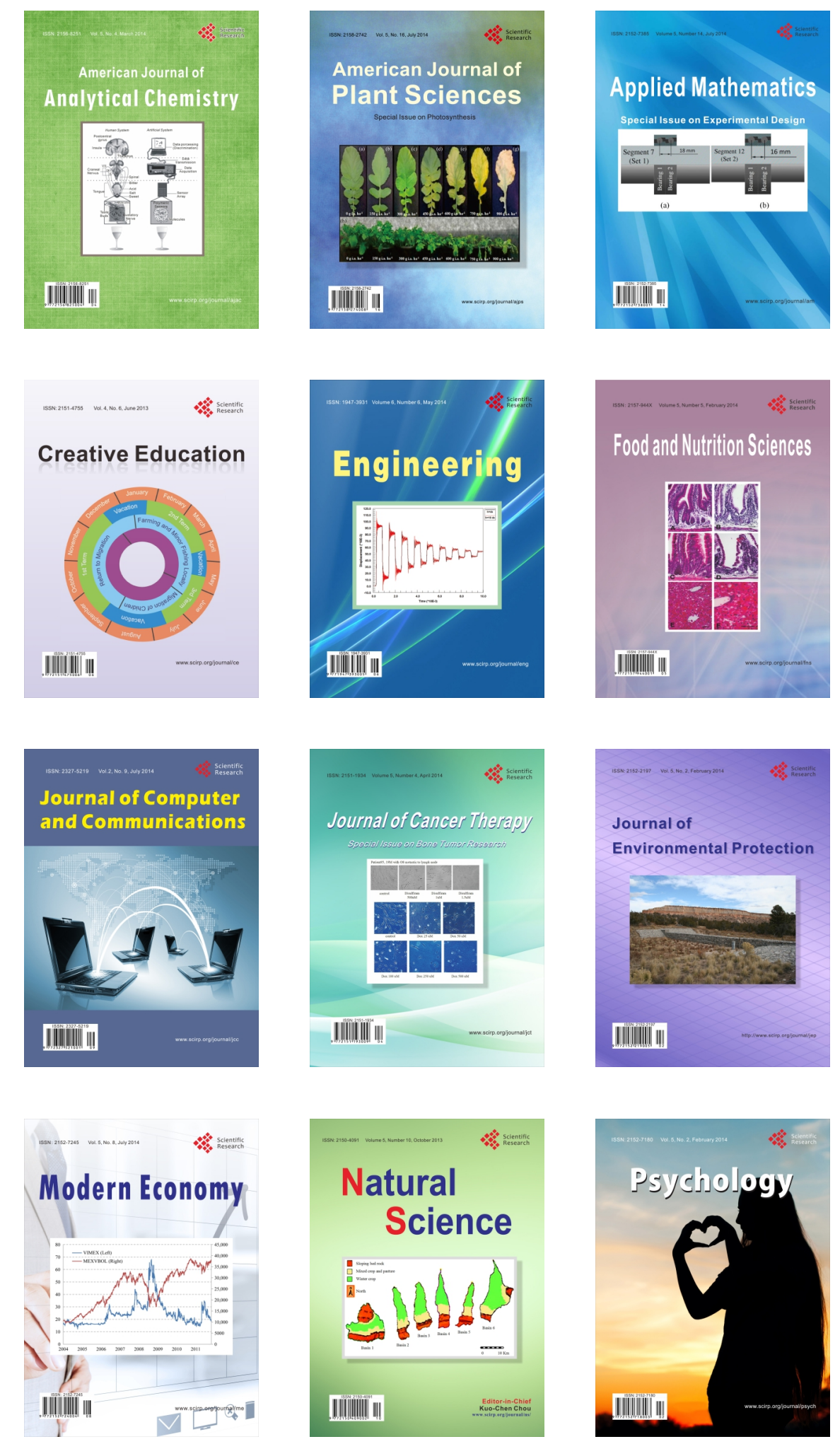